\title{
Structure, long persistent luminescent properties and mechanism of a novel efficient red emitting $\mathrm{Ca}_{2} \mathrm{Ga}_{2} \mathrm{GeO}_{7}: \mathrm{Pr}^{3+}$ phosphor
}

\author{
Zehua Zou ${ }^{1}$, Cheng Cao ${ }^{1}$, Teng Zhang ${ }^{1}$, Lin Feng ${ }^{1}$, Jiachi Zhang $*^{1}$, Zhipeng $\mathrm{Ci}{ }^{*}{ }^{1}$, \\ Zhiya Zhang ${ }^{1}$, Yuhua Wang ${ }^{1}$ \\ 1, Key Laboratory for Magnetism Magnetic Materials of the Ministry of Education, \\ Lanzhou University, Lanzhou 730000, P. R. China.
}

Corresponding author: zhangjch@lzu.edu.cn; cizhp@lzu.edu.cn

$$
\text { Tel.: +86-931-8912772, Fax: +86-931-8913554 }
$$

\section{ABSTRACT:}

A novel red emitting long persistent luminescent phosphor $\mathrm{Ca}_{2} \mathrm{Ga}_{2} \mathrm{GeO}_{7}: \mathrm{Pr}^{3+}$ (2217) was developed by solid state method at $1300{ }^{\circ} \mathrm{C}$ in air. The refined crystal structure of $\mathrm{Ca}_{2} \mathrm{Ga}_{2} \mathrm{GeO}_{7}$ host was solved. The intense red long persistent luminescence originates from the $f-f$ transitions of $\mathrm{Pr}^{3+}$ centers at highly disordered $\mathrm{Ca}^{2+}$ sites in $\mathrm{CaO}_{8}$ polyhedrons. It can be properly recorded for $1.5 \mathrm{~h}$ by the definition of $0.32 \mathrm{mcd} / \mathrm{m}^{2}$ and is actually visible for more than 5 h by dark-adapted vision in darkness. At least one type of intrinsic lattice defects of the $\mathrm{Ca}_{2} \mathrm{Ga}_{2} \mathrm{GeO}_{7}$ host as proper shallow traps exists in $\mathrm{Ca}_{2} \mathrm{Ga}_{2} \mathrm{GeO}_{7}: \mathrm{Pr}^{3+}$ material and the depth of the traps is calculated to be 0.59 $\mathrm{eV}$, which is very suitable for long persistent luminescence. It reveals that the $\operatorname{Pr}^{3+}$ dopants not only act as emitters but also increase the density of these significant intrinsic traps, resulting in the efficient persistent luminescence of $\operatorname{Pr}^{3+}$. The 
retrapping and tunneling effects are demonstrated to be responsible for the nonexponential and much slower decay behaviors in the late slow-decay stage ( $t>$ $300 \mathrm{~s})$. A new parameter of threshold depth is firstly defined for the evaluation of the retrapping and tunneling effects and it is calculated to be $0.76 \mathrm{eV}$ in this case by a classic multi-peak fitting method based on general-order kinetics. Finally, the long persistent luminescence mechanism of this $\mathrm{Ca}_{2} \mathrm{Ga}_{2} \mathrm{GeO}_{7}: \mathrm{Pr}^{3+}$ phosphor is proposed according to these investigation results.

Keywords: Long persistent luminescence; Phosphor; $\mathrm{Ca}_{2} \mathrm{Ga}_{2} \mathrm{GeO}_{7}: \mathrm{Pr}^{3+}$

\section{Introduction}

Long persistent luminescence (LPL) is a particular optical phenomenon whereby a material remains luminescence for an appreciable time after the high energy excitation removed [1-6]. The first record of an LPL material, which was found in

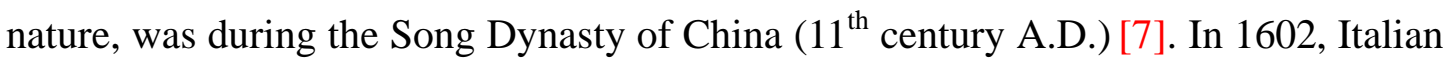
V. Casciarolo discovered the famous Bolognian stone, which could emit blue-violet light for a few minutes in darkness [8]. Although numerous LPL materials have been previously reported, it was only in 1996 that this field of research began to attract much wider interest due to the discovery of the highly bright LPL of $\mathrm{SrAl}_{2} \mathrm{O}_{4}: \mathrm{Eu}^{2+}, \mathrm{Dy}^{3+}$ phosphor by T. Matsuzawa [9]. Since then, at least one thousand papers were published about LLP including active researches for application in various important fields. For example, emergency signage used in case of electricity failures is one of the main application [10-11], but other application were also proposed such as optical storage media [12-13], vivo bio-imaging [14], drug carriers [10], solar energy ultilization[15] and even photocatalysis [16-17]. Up to now, 
$\mathrm{SrAl}_{2} \mathrm{O}_{4}: \mathrm{Eu}^{2+}, \mathrm{Dy}^{3+}$ (green), $\mathrm{CaAl}_{2} \mathrm{O}_{4}: \mathrm{Eu}^{2+}, \mathrm{Nd}^{3+}$ (blue) and $\mathrm{Y}_{2} \mathrm{O}_{2} \mathrm{~S}: \mathrm{Eu}^{3+}, \mathrm{Ti}^{3+}, \mathrm{Mg}^{2+}$ (red) are generally acknowledged to be the representative LPL phosphors [7-9]. However, compared with the green and blue LLP phosphors, red LLP materials which suffer from unsatisfying persistent time or stability are still far beyond practical application. Thus, it is urgent to explore the possibilities of new systems that may be used as efficient red LPL phosphors. Furthermore, the LPL mechanism still remains unclear enough to limit the development of these materials. Therefore, it is still necessary for us to continue the development of new LPL phosphors for better understanding of the LPL mechanism.

In LPL phosphors, two kinds of active centers are involved: emitters and traps. Emitters are the centers capable of luminous emission after being excited. Traps usually don't emit radiation, but conserve excitation energy and release it gradually to the emitters owing to thermal or other physical stimulations [18]. In this context, the emitters mainly determine the emission wavelength of LPL phosphors, while the natures of traps dominate the LPL intensity and time (for examples: type, depth and distribution of traps), which are generally dependent on the intrinsic lattice defects or impurities. Therefore, in the design of a new efficient red LPL phosphor, a suitable emitter capable of emitting red light and a proper host lattice capable of creating appropriate traps are required. For red photoluminescence (PL), the trivalent $\mathrm{Eu}^{3+}$, $\mathrm{Sm}^{3+}$ and $\mathrm{Pr}^{3+}$ ions, are favorable luminescent centers in solids because of their narrow-band emissions in red region. For host, the alkaline earth gallogermanates, such as ( $\mathrm{Sr}, \mathrm{Ca})_{3} \mathrm{Ga}_{2} \mathrm{Ge}_{4} \mathrm{O}_{14}$ (32414) [19], $\mathrm{La}_{3} \mathrm{Ga}_{5} \mathrm{GeO}_{14}$ (35114) [20], $\mathrm{Zn}_{3} \mathrm{Ga}_{2} \mathrm{Ge}_{2} \mathrm{O}_{10}$ (23310) [18], $\mathrm{Zn}_{3} \mathrm{Ga}_{2} \mathrm{GeO}_{8}$ (3218) [21] and $\mathrm{Ca}_{3} \mathrm{Ga}_{2} \mathrm{Ge}_{3} \mathrm{O}_{12}$ (32312) [13], have been previously used as the hosts for achieving efficient near-infrared (near-IR) LPL. It reveals that the alkaline earth gallogermanates could provide numerous distorted 
polyhedral sites for substitution, resulting in the presence of significant intrinsic lattice defects as traps around the emitters. However, the previously reported references mainly focused on the $\mathrm{Cr}^{3+}$ activated near-IR LPL in gallogermanates, while the $\mathrm{Eu}^{3+}, \mathrm{Sm}^{3+}$ and $\mathrm{Pr}^{3+}$ activated red LPL in alkaline earth gallogermanates are rarely reported. Moreover, the $\mathrm{Ca}_{2} \mathrm{Ga}_{2} \mathrm{GeO}_{7}$ (2217) with highly distorted dodecahedrons $\left(\mathrm{CaO}_{8}\right.$ group) structure is a potential new host for achieving efficient LPL, but the refined crystal structure and the PL / LPL luminescence properties of $\mathrm{Ca}_{2} \mathrm{Ga}_{2} \mathrm{GeO}_{7}: \mathrm{RE}^{3+}$ materials have never been reported thus far.

In this work, we have successfully developed a novel efficient $\operatorname{Pr}^{3+}$ doped calcium gallogermanate red LPL phosphor (2217) by traditional solid state method at $1300^{\circ} \mathrm{C}$ in air atmosphere. Particularly, the intense red LPL of the optimal $\mathrm{Ca}_{2} \mathrm{Ga}_{2} \mathrm{GeO}_{7}: \mathrm{Pr}^{3+}$ sample can be recorded for approximately $1.5 \mathrm{~h}\left(0.32 \mathrm{mcd} / \mathrm{m}^{2}\right)$ and is visible for even more than $5 \mathrm{~h}$ in dark by using dark-adapted vision. This good result is sufficiently encouraging for the initiation of a more thorough investigation. Several classical investigation methods, including Rietveld refinement, LPL decay behaviors, thermoluminescence, fading experiments, and multi-peak fitting based on general-order kinetics, are applied in this study to examine the refined crystal structure of the $\mathrm{Ca}_{2} \mathrm{Ga}_{2} \mathrm{GeO}_{7}$ host and the $\mathrm{LPL}$ mechanisms of the $\mathrm{Ca}_{2} \mathrm{Ga}_{2} \mathrm{GeO}_{7}: \mathrm{Pr}^{3+}$ phosphors in details.

\section{Experimental section}

\subsection{Materials and synthesis}

$\mathrm{Ca}_{2} \mathrm{Ga}_{2} \mathrm{GeO}_{7}: \mathrm{Pr}^{3+}$ phosphors were synthesized by a traditional solid state method. The raw materials were $\mathrm{CaCO}_{3}$ (A.R.), $\mathrm{Ga}_{2} \mathrm{O}_{3}$ (99.99\%), $\mathrm{GeO}_{2}$ (99.99\%) and $\mathrm{Pr}_{6} \mathrm{O}_{11}$ (99.99\%), which were used directly without any further treatment. The stoichiometric 
stating materials were thoroughly homogenized (all grinding was performed using an agate pestle and mortar) the mixture was transferred into an alumina crucible and then loaded into a muffle furnace. Then the mixed samples were sintered at $1300{ }^{\circ} \mathrm{C}$ for $2 \mathrm{~h}$ in air. The obtained samples were cooled to room temperature and then ground again in an agate mortar. Finally, the $\mathrm{Ca}_{2} \mathrm{Ga}_{2} \mathrm{GeO}_{7}: \mathrm{Pr}^{3+}$ powders were obtained.

\subsection{Measurements and characterization}

A Rigaku D/Max-2400 X-ray diffractometer (XRD) was employed to check the phases of the obtained samples. Photoluminescence (PL) spectra were recorded using a FLS-920T spectrophotometer (Edinburgh Instruments Ltd, Edinburgh, U.K.) with a $450 \mathrm{~W}$ xenon arc lamp (Xe900) as the light source. LPL decay curve measurements were taken with a PR305 LPL instrument (Zhejiang University Sensing Instrument Co. Ltd., Hangzhou, China). The thermoluminescence (TL) curves were measured using a FJ-417A TL meter (Beijing Nuclear Instrument Factory, Beijing, China). All samples were first exposed to radiation using an UV lamp $(254 \mathrm{~nm})$ and then heated from room temperature to $673 \mathrm{~K}$ at a rate of $1 \mathrm{Ks}^{-1}$. All measurements were carried out at room temperature except for TL measurements.

\section{Results and discussion}

\subsection{Structural analysis}

Fig. 1 shows the results of Rietveld refinement for the $\mathrm{Ca}_{2} \mathrm{Ga}_{2} \mathrm{GeO}_{7}$ host (6786 cycles with 156 variables using the GSAS program), the black crosses and red solid lines depict the observed and calculated patterns, respectively. The refinement factors

of the $\chi^{2}$, the weighted profile $R$-factor $\left(R_{\mathrm{wp}}\right)$ and the expected $R$ factor $\left(R_{\mathrm{p}}\right)$ are determined to be $1.771,9.30 \%$ and $7.40 \%$, respectively, indicating that the refined results are reliable. The refined crystallographic data and the atom coordinates of the 
$\mathrm{Ca}_{2} \mathrm{Ga}_{2} \mathrm{GeO}_{7}$ host are listed in Table 1 and Table 2, respectively. According to the results, the $\mathrm{Ca}_{2} \mathrm{Ga}_{2} \mathrm{GeO}_{7}$ structure belongs to tetragonal phase and space group $\mathrm{P}$-421 m (113) with medium lattice parameters $a=b=7.8938(0) \AA, c=5.2096(0) \AA$. As shown in inset of Fig. 1 , the unit cell of $\mathrm{Ca}_{2} \mathrm{Ga}_{2} \mathrm{GeO}_{7}$ contains two formula units $(Z=$ 2), giving a total of 24 ions per unit cell. Of the 24 ions, 14 are oxygen, and it is convenient to visualize their distribution in terms of cation polyhedra. The $\mathrm{Ca}^{2+}$, $\mathrm{Ga}^{3+} / \mathrm{Ge}^{4+}$ cations are surrounded by eight and four oxygen anions forming a dodecahedron and a tetrahedron, respectively. The doped $\mathrm{Pr}^{3+}$ ions prefer to occupy the dodecahedral sites of $\mathrm{Ca}^{2+}$ in the $\mathrm{Ca}_{2} \mathrm{Ga}_{2} \mathrm{GeO}_{7}$ host because of the approximate ionic radii between $\mathrm{Ca}^{2+}(r=1.120 \AA$ with $\mathrm{CN}=8)$ and $\operatorname{Pr}^{3+}(r=1.126 \AA$ with $\mathrm{CN}=$ 8). On the other hand, as listed in Table 3, the $\mathrm{CaO}_{8}$ dodecahedron exhibits eight Ca-O bonds with average distance value of $2.36 \AA$, and the $\mathrm{GaO}_{4}$ / $(\mathrm{Ga}, \mathrm{Ge}) \mathrm{O}_{4}$ tetrahedron exhibits four Ga-O / (Ga,Ge)-O bonds with average distance value of $1.80 \AA$ / $1.78 \AA$. By comparison, the bond distances of the $\mathrm{Ga}^{3+}$ and $\mathrm{Ge}^{4+}$ sites are too small for $\mathrm{Pr}^{3+}$ to occupy while the $\mathrm{CaO}_{8}$ dodecahedron provides more reasonable crystallographic spaces for $\operatorname{Pr}^{3+}$ dopants. This result further confirms that the $\operatorname{Pr}^{3+}$ ions should enter into the only $\mathrm{Ca}^{2+}$ sites in the $\mathrm{Ca}_{2} \mathrm{Ga}_{2} \mathrm{GeO}_{7}$ host. Particularly, it is important to note that the $\mathrm{Ca}^{2+}$ sites are coordinated with eight oxygen atoms and located in the highly distorted dodecahedral sites as shown in Fig. 1 and Table 3, implying the possible distribution of significant intrinsic lattice defects as traps. Therefore, the $\mathrm{Ca}_{2} \mathrm{Ga}_{2} \mathrm{GeO}_{7}: \operatorname{Pr}^{3+}$ phosphors can be expected to exhibit efficient red LPL.

As demonstrated by the XRD patterns of the as-synthesized $\mathrm{Ca}_{2} \mathrm{Ga}_{2} \mathrm{GeO}_{7}$ host and the typical $\mathrm{Ca}_{2} \mathrm{Ga}_{2} \mathrm{GeO}_{7}: \mathrm{Pr}^{3+}$ samples in Fig. 2, all the diffraction peaks are well indexed to those of the tetragonal $\mathrm{Ca}_{2} \mathrm{Ga}_{2} \mathrm{GeO}_{7}$ phase (JCPDS No. 72-2008). The doping of praseodymium ions does not induce any other phases, indicating the 
successful incorporation of the activators into the $\mathrm{Ca}_{2} \mathrm{Ga}_{2} \mathrm{GeO}_{7}$ host.

\subsection{Photoluminescent and long persistent luminescent properties}

Fig. 3 shows the PL excitation $\left(\mathrm{a}, \lambda_{\mathrm{em}}=603 \mathrm{~nm}\right)$ and PL emission $\left(\mathrm{b}, \lambda_{\mathrm{em}}=260 \mathrm{~nm}\right)$ spectra of the typical $\mathrm{Ca}_{2} \mathrm{Ga}_{2} \mathrm{GeO}_{7}: 0.1 \% \operatorname{Pr}^{3+}$ sample. It exhibits an intense excitation band centered at $260 \mathrm{~nm}$ and a serial of narrow peaks in the range $430-500 \mathrm{~nm}$ as shown in Fig. 3(a). The former $(260 \mathrm{~nm})$ can be ascribed to the absorption of $\mathrm{Ca}_{2} \mathrm{Ga}_{2} \mathrm{GeO}_{7}$ host and the latter is attributed to the $f-f$ transitions $\left({ }^{3} \mathrm{H}_{4} \rightarrow{ }^{3} \mathrm{P}_{j}, j=0,1\right.$ and 2) of $\operatorname{Pr}^{3+}$ ions [1, 22]. Moreover, under $260 \mathrm{~nm}$ excitation, the PL emission bands in the range 450-750 $\mathrm{nm}$ can be assigned unambiguously to the characteristic transitions $\left({ }^{3} \mathrm{P}_{0} \rightarrow{ }^{3} \mathrm{H}_{4},{ }^{3} \mathrm{H}_{6},{ }^{3} \mathrm{~F}_{2},{ }^{3} \mathrm{~F}_{3},{ }^{3} \mathrm{~F}_{4} ;{ }^{1} \mathrm{D}_{2} \rightarrow{ }^{3} \mathrm{H}_{4}\right)$ of $\mathrm{Pr}^{3+}$ centers in Fig. 3(b) [1, 22]. Fig. 3(c) shows the LPL emission spectrum of the typical $\mathrm{Ca}_{2} \mathrm{Ga}_{2} \mathrm{GeO}_{7}: 0.1 \% \mathrm{Pr}^{3+}$ sample, recorded after UV (254 nm) lamp irradiation for $60 \mathrm{~s}$ and again after a delay of 30 s. Both the PL and LPL spectra are found to be similar, suggesting identical emission centers in the PL and LPL processes.

To determine the optimal contents of $\operatorname{Pr}^{3+}$ dopants, Fig. 4 gives the LPL spectra of the $\mathrm{Ca}_{2} \mathrm{Ga}_{2} \mathrm{GeO}_{7}: \mathrm{Pr}^{3+}(x=0.06 \%, 0.08 \%, 0.1 \%, 0.3 \%$, and $0.5 \%$, respectively $)$ samples measured after UV (254 nm) lamp irradiation for $60 \mathrm{~s}$ and again after a delay of 30 s. Accordingly, the $\mathrm{Ca}_{2} \mathrm{Ga}_{2} \mathrm{GeO}_{7}: 0.1 \% \mathrm{Pr}^{3+}$ is selected as the optimal sample in the further study. Fig. 4 also exhibits the Commission Internationale de l'Éclairage (CIE) chromaticity coordinates based on these LPL spectra and the LPL image of the optimal $\mathrm{Ca}_{2} \mathrm{Ga}_{2} \mathrm{GeO}_{7}: 0.1 \% \mathrm{Pr}^{3+}$ sample after $\mathrm{UV}$ irradiation for $60 \mathrm{~s}$ in dark condition. Bright red LPL is clearly observed and the CIE coordinates are calculated to be $(0.55$, $0.36)$. 


\subsection{Long persistent luminescent decay behaviors}

Fig. 5 shows the LPL decay curves of the $\mathrm{Ca}_{2} \mathrm{Ga}_{2} \mathrm{GeO}_{7}: \mathrm{Pr}^{3+}(x=0.06 \%, 0.08 \%$, $0.1 \%, 0.3 \%$, and $0.5 \%$, respectively) samples ,which were recorded immediately after UV (254 nm) lamp irradiation for 15 min. At first, all curves (LPL intensities) decrease quickly but then very slowly, and the LPL of the optimal $\mathrm{Ca}_{2} \mathrm{Ga}_{2} \mathrm{GeO}_{7}: 0.1 \% \mathrm{Pr}^{3+}$ sample can last for approximately $5500 \mathrm{~s}$, before it drops below the threshold value: $0.32 \mathrm{mcd} / \mathrm{m}^{2}$ (a value commonly used by the safety signage industry). Since the eye sensitivity is about 100 times better than this value $\left(0.32 \mathrm{mcd} / \mathrm{m}^{2}\right)$, we can actually observe the LPL for even more than $5 \mathrm{~h}$ by using the dark-adapted vision in complete darkness.

Naturally, it would be of interest to determine the LPL decay model by fitting these curves. In previous researches, the majority fit the LPL decay curves in linear-linear or single logic plots by using a function of the exponential terms and calculate the so-called "LPL decay parameters" such as $I_{0}, A$, and $\tau$. Consequently, a decay curve is usually divided into multiple exponential components generally referred to as "fast," “medium,” or "slow.” However, such results reflect a gross misunderstanding of LPL decay. Generally, luminescent materials can be classified, according to the decay of their light emission $L$, into two broad categories: those with an exponential decay, $L$ $\propto \exp ^{-t / \tau}$, and those with a power law decay $L \propto t^{-m}$. In fact, many materials, particularly those assigned to the latter category, display both types of decay behavior, according to a power law in some cases and exponentially in others [23]. Unlike the exponentially decaying part, in which the rate is determined by the lifetimes of the radiative states, the power law decay rate may be sensitive to the empty luminescent centers and the filled traps, the latter of which is determined by the rate at which retrapping and recombination occur [24]. Therefore, when the LPL decay appears to 
be nonexponential, an alternative approach concerning the retrapping effect should be employed.

A luminescence decay process is crucial to luminescence dynamic. As stated before, almost all of the LPL decay curves exhibited only in one type (linear-linear or single logic) plots can be fitted exponentially well within the entire time range of the decay measurement. However, the decay curves of LPL phosphors should be also given in more types of plots like double logarithm, which is the only way to see the decay processes [25-26]. The decay and fitting curves of typical $\mathrm{Ca}_{2} \mathrm{Ga}_{2} \mathrm{GeO}_{7}: 0.1 \% \mathrm{Pr}^{3+}$ are presented in Fig. 6. As shown in Fig. 6(a-c), it is clearly exhibited that the measured results in the early stage is well-fitted into biexponential function as follows:

$$
I(t)=I_{0}+A_{1} \exp \left(-\frac{t}{\tau_{1}}\right)+A_{2} \exp \left(-\frac{t}{\tau_{2}}\right)
$$

Here, $I(\mathrm{t})$ and $I_{0}$ are the LPL intensity at time $\mathrm{t}$ and $0, A_{1}$ and $A_{2}$ are constants, $t$ is time, and $\tau_{1}$ and $\tau_{2}$ are the decay times. The fitting parameters were also listed in Table 4 . However, the slow-decay stage $(t>300 \mathrm{~s}$ ) does not match with the fitting curve in both the single and double logic plots, though the high fitting accuracy can be observed in linear-linear plots. Actually, most exponential equations like Eq. (1) can be obtained from the initial luminescence decay function as follows [26]:

$$
I(\mathrm{t})=A \exp \left(-\frac{t}{\tau}\right)
$$

Eq. (2) is known as the first-order kinetics mechanism based on it that the retrapping probability of the electrons is neglected. The actual situation may be that the retrapping can be ignored in the early stage $(\mathrm{t}<300 \mathrm{~s})$ resulting in the well-fitting with the exponential curve, then the retrapping becomes dominate which contributes the LPL decay time in the later stage ( $\mathrm{t}>300 \mathrm{~s}$ ), leading to the deviation of the curves, no more sticks to the first-order kinetics mode. Actually, the existing formulas are 
always in accordance with the experimental decay data in the initial fast decay stage [26-27]. This result is due to that every charge carrier managing to thermally escape from a trap can immediately move to $\mathrm{Pr}^{3+}$ levels for efficient recombination through the conduction band, and will not be captured by another trap. This would lead to a rapid LPL decay and an exponential LPL decay profile in the early decay stage $(t<$ $300 \mathrm{~s})$. However, in the late slow-decay stage ( $t>300 \mathrm{~s})$, the exponential fitting of the decay is no longer possible, which means that the retrapping is beginning to work. The retrapping effect is generally associated with a variation of trap depth. As the trapped carriers are released, the real-time trap depth becomes deeper; thus, it becomes more difficult for the later carriers to move to $\mathrm{Pr}^{3+}$ levels for recombination through the conduction band. At this stage, a carrier that manages to escape a trap can be immediately recaptured by another trap, i.e., the retrapping effect. Consequently, the recombination rate would be slower, leading to much weaker LPL intensity, and therefore, a significantly longer LPL time.

On the other hand, the retrapping effect is usually accompanied by the tunneling effect. Fig. 6(d) presents the reciprocal of the LPL intensity as a function of time, i.e., $I^{-1}=f(\mathrm{t})$. This relationship is very close to linear (except $t<300 \mathrm{~s}$ ), and the curve decay approximately as $t^{-1}$ has very important implications in the choice of an acceptable retrapping model. Also, it appears that the linear dependence of $I$ versus $t^{-a}$ is a sign that the LPL occurs through a quantum tunneling-related process [23].

In summary, the LPL decay process of the $\mathrm{Ca}_{2} \mathrm{Ga}_{2} \mathrm{GeO}_{7}: 0.1 \% \operatorname{Pr}^{3+}$ sample consists of two stages. In the early stage $(t<300 \mathrm{~s})$, the trapped electrons move to $\mathrm{Pr}^{3+}$ through the conduction band for efficient recombination, which results in a rapid and exponential decay. In the late stage ( $t>300 \mathrm{~s})$, the retrapping effect is more active and thus the trapped electrons have to move to the excited states of $\operatorname{Pr}^{3+}$ via a quantum 
tunneling process, leading to a much slower and nonexponential (power law) decay behavior.

\subsection{Thermoluminescence and fading experiments}

Fig. 7 shows the TL glow curves of the $\mathrm{Ca}_{2} \mathrm{Ga}_{2} \mathrm{GeO}_{7}$ host and the $\mathrm{Ca}_{2} \mathrm{Ga}_{2} \mathrm{GeO}_{7}: \mathrm{Pr}^{3+}(x=0 \%, 0.06 \%, 0.08 \%, 0.1 \%, 0.3 \%$, and $0.5 \%$, respectively $)$ samples recorded immediately after UV lamp irradiation for 15 min. Because the TL signal of the $\mathrm{Ca}_{2} \mathrm{Ga}_{2} \mathrm{GeO}_{7}$ host is so weak that it produced a nearly straight line in Fig. 7(b), it is shown alone in Fig. 7(a) for more detail. It is significant that the $\mathrm{Ca}_{2} \mathrm{Ga}_{2} \mathrm{GeO}_{7}$ host clearly exhibits a single $\mathrm{TL}$ band at approximately $334 \mathrm{~K}$, which is similar to those of $\operatorname{Pr}^{3+}$ doped samples. The accurate attribution of this TL band remains an open question, but it is almost certain that that this TL band at low temperature (334 K) corresponds to at least one type of shallow traps and it must be associated with the intrinsic lattice defects of $\mathrm{Ca}_{2} \mathrm{Ga}_{2} \mathrm{GeO}_{7}$ host. As shown in Fig. 7, it also indicates that the $\operatorname{Pr}^{3+}$ dopants not only act as emitters but also greatly increase the content of the intrinsic lattice defects (shallow traps) due to the $\mathrm{Ca}_{2} \mathrm{Ga}_{2} \mathrm{GeO}_{7}$ host, resulting in the efficient LPL.

To show the critical role of these shallow traps on LPL process in greater detail, that TL fading experiments which are measured TL glow curves with different delay times after ceasing the UV irradiation are conducted. The TL glow curves of the optimal $\mathrm{Ca}_{2} \mathrm{Ga}_{2} \mathrm{GeO}_{7}: 0.1 \% \mathrm{Pr}^{3+}$ sample after UV irradiation for 15 min and then after different delay times are exhibited in Fig. 8. As the delay time increases, it is found that not only the TL intensity gradually decreases, but also the TL peak shifts slightly toward the higher temperature. The peak maximum is located at $334 \mathrm{~K}$ for the $5 \mathrm{~s}$ duration and has shifted to $359 \mathrm{~K}$ after $5400 \mathrm{~s}$. It is well known that the position of TL 
bands represents the trap depth, whereas lower (higher) temperature corresponds to shallow (deeper) traps. This result indicates that trap depth is dynamic and trends to be increasing during the decay process. As mentioned above, the retrapping effect is beginning to work after $300 \mathrm{~s}$ decay duration, and thus the retrapping effect must be associated with a threshold value of trap depth at the point of $300 \mathrm{~s}$ duration.

To estimate the trap depth and the kinetics of the LPL process in the example of the as-prepared $\mathrm{Ca}_{2} \mathrm{Ga}_{2} \mathrm{GeO}_{7}: \mathrm{Pr}^{3+}$ material, we introduce a classical multi-peak fitting method developed by Chen et al [28]. Considering that the retrapping effect cannot be neglected in this case, as mentioned above, the usual general-order kinetics expression should be utilized to describe the TL glow curves. The general-order expression describing the TL intensity $I$ as a function of the temperature $T$ is:

$$
I(T)=s n_{o} \exp \left(-\frac{E}{k T}\right)\left[1+(b-1) \frac{s}{\beta} \times \int_{T_{0}}^{T} \exp \left(-\frac{E}{k T^{\prime}}\right) d T^{\prime}\right]^{-\frac{b}{b-1}},
$$

where $E$ is the trap depth (activation energy), and $n_{0}$ is the trap concentration of trapped carriers such as electrons and holes at the moment; $k$ is the Boltzmann constant; and $\beta$ is the heating rate ( $1 \mathrm{~K} / \mathrm{s}$ for our experiment). Here, $s$ is the frequency factor, which is expected to be less than the vibration frequency of the lattice, $10^{12}$ $\mathrm{s}^{-1}$. Furthermore, $b$ is the kinetics order parameter, which indicates the order of the trapping process; $b$ equal to 1 is direct recombination, and $b$ greater than 1 indicates retrapping of the carriers. Because it is very difficult to fit a serial of experimental data by a function containing an integral, Eq. (3) should be simplified to Eq. (4) according to the integration reported by Kitis [29], and the convenient parameters of $I_{m}, T_{m}, s$, and $n_{0}$ can be introduced in the following equations:

$$
I(T)=I_{m} b^{\frac{b}{b-1}} \exp \left(\frac{E}{k T} \frac{T-T_{m}}{T_{m}}\right) \times\left[(b-1)(1-\Delta) \frac{T^{2}}{T_{m}^{2}} \exp \left(\frac{E}{k T} \frac{T-T_{m}}{T_{m}}\right)+Z_{m}\right]^{-\frac{b}{b-1}},
$$


with $\Delta=\frac{2 k T}{E}$ and $Z_{m}=1+(b-1) \frac{2 k T_{m}}{E}$,

where $I_{m}$ is the glow-peak maximum intensity, $T_{m}$ is the temperature at the maximum, and $t_{n}$ is the theoretical decay time at $T_{n} \mathrm{~K}$.

On the basis of the above general-order kinetics expression, all TL glow curves can be well fitted by the multi-peak fitting method. The deconvolution of the TL glow curve of the optimal $\mathrm{Ca}_{2} \mathrm{Ga}_{2} \mathrm{GeO}_{7}: 0.1 \% \mathrm{Pr}^{3+}$ sample is given in Fig. 7 (c) as a representative. Accordingly, the calculated traps depths $(E)$ for all of the measured TL glow curves after the different time delays are exhibited in Fig. 8. It reveals that as the delay time increases, the trap depth $(E)$ gradually increases as well and it has increased to be as deep as $0.76 \mathrm{eV}$ after decay for $300 \mathrm{~s}$. At this point, the retrapping becomes dominant meaning that the trapped electrons are no longer capable of moving to $\operatorname{Pr}^{3+}$ through conduction band but are thermally promoted into the shallow tunneling state, and then tunnel to the excited state of nearby $\mathrm{Pr}^{3+}$ ions for LPL. Accordingly, the threshold value of trap depth for the retrapping and tunneling effects should be determined to be about $0.76 \mathrm{eV}$ in this case.

Obviously, the tunneling rate is slow and always occurs alongside the retrapping in the late stage of decay. This process can effectively explain the relatively weaker but much longer LPL emitted during the slow-decay process.

\subsection{Long persistent luminescent mechanisms}

On the basis of the above results and discussion, the LPL mechanism of this $\mathrm{Ca}_{2} \mathrm{Ga}_{2} \mathrm{GeO}_{7}: \mathrm{Pr}^{3+}$ phosphor is proposed in a schematic diagram in Fig. 9. Under UV lamp excitation, the electrons are promoted to the conduction band (process 1). The electrons are subsequently captured by the shallow traps below the conduction band (process 2). During thermal disturbance at room temperature, the captured electrons 
are gradually released from the shallow traps and backtracked to the excited levels of $\operatorname{Pr}^{3+}$ via the conduction band (process 3). Finally, these electrons recombine to generate intense red and exponential LPL (process 4). After a decay for $300 \mathrm{~s}$, the transfer of electrons through the conduction band is in a much lower rate owing to the much deeper trap depth $(0.76 \mathrm{eV})$. At this point, the retrapping effect, that free electrons in the conduction band are trapped again by the shallow traps, is more effective (process 5). Finally, the trapped electrons must be thermally promoted to be located at their shallow tunneling states (approximately $0.76 \mathrm{eV}$ ) and tunnel a short distance to arrive at the excited states of $\operatorname{Pr}^{3+}$ (process 6) for weaker, nonexponential but much longer LPL (process 7).

\section{Conclusions}

We obtained a novel red LPL phosphor $\mathrm{Ca}_{2} \mathrm{Ga}_{2} \mathrm{GeO}_{7}: \mathrm{Pr}^{3+}$ (2217) by conventional solid state method at $1300{ }^{\circ} \mathrm{C}$ in air. The LPL spectrum shows characteristic emissions due to the $f$ - $f$ transitions of $\mathrm{Pr}^{3+}$ at eight coordinated $\mathrm{Ca}^{2+}$ sites in highly disordered $\mathrm{CaO}_{8}$ polyhedrons and the color coordinates are calculated to be $(0.55,0.36)$. The LPL of the optimal $\mathrm{Ca}_{2} \mathrm{Ga}_{2} \mathrm{GeO}_{7}: \mathrm{Pr}^{3+}$ sample can be recorded for approximately $1.5 \mathrm{~h}$ $\left(0.32 \mathrm{mcd} / \mathrm{m}^{2}\right)$ and is visible for even more than $5 \mathrm{~h}$ in dark by using dark-adapted vision. Thermoluminescence shows that there is at least one type of intrinsic lattice defects in $\mathrm{Ca}_{2} \mathrm{Ga}_{2} \mathrm{GeO}_{7}$ host, which act as shallow traps $(0.59 \mathrm{eV})$. The $\operatorname{Pr}^{3+}$ dopants not only play important roles as emitters but also increase the density of these significant intrinsic traps, leading to the efficient LPL. The investigations of decay behaviors show that the retrapping and tunneling effects are dominant in the late slow-decay stage ( $t>300 \mathrm{~s}$ ), resulting in the nonexponential and slow decay profiles. By a classic multi-peak fitting method based on general-order kinetics, the new 
parameter of the threshold depth involved in the retrapping and tunneling effects is defined for the first time and it is determined to be about $0.76 \mathrm{eV}$ in this case. Finally, the LPL mechanism of the $\mathrm{Ca}_{2} \mathrm{Ga}_{2} \mathrm{GeO}_{7}: \mathrm{Pr}^{3+}$ phosphor is proposed based on these results.

\section{Acknowledgements}

This work was supported by the National Nature Science Foundation of China (Nos. 10904057, 51202099), the Fundamental Research Funds for Central Universities (No. Lzjbky-2015-112), and the National Science Foundation for Fostering Talents in Basic Research of the National Natural Science Foundation of China (Nos. 041105 and 041106).

\section{References}

[1] Y.H. Jin, Y.H. Hu, R. Chen, Y.R. Fu, G.F. Ju, Z.F. Mu, J. Lin, Z.H. Wang, F.H. Xue, Q. Zhang, Synthesis and luminescence properties of a novel yellowish-pink emissive long persistent luminescence phosphor $\mathrm{Cd}_{2} \mathrm{GeO}_{4}: \mathrm{Pr}^{3+}$, J. Alloys Compd. 623 (2015) $255-260$

[2] D.Y. Zhang, M.M. Shi, Y.W. S. Y.Y. Guo, C.K. Chang, Long afterglow property of $\mathrm{Er}^{3+}$ doped $\mathrm{Ca}_{2} \mathrm{SnO}_{4}$ phosphor, J. Alloys Compd. 667(2016) 235-239.

[3] T. Xie, H.X. Guo, J.Y. Zhang, C. Odetola, Y.N. He, H. Lin, G.L. Chen, Z.S. Zheng, Phosphorescence behavior and photoluminescence mechanism of $\mathrm{Dy}^{3+}$ sensitized $\beta-\mathrm{Zn}_{3}\left(\mathrm{PO}_{4}\right)_{2}: \mathrm{Mn}^{2+}$ phosphor, J. Alloys Compd. 642 (2015) 225-231.

[4] C. Zhang, X.Y. Gong, C.Y. Deng, The phase transition of color-tunable long afterglow phosphors $\mathrm{Sr}_{1.94-\mathrm{x}} \mathrm{Ba}_{\mathrm{x}} \mathrm{MgSi}_{2} \mathrm{O}_{7}: \mathrm{Eu}^{2+}{ }_{0.01}, \mathrm{Dy}^{3+}{ }_{0.05}$, J. Alloys Compd. 657 
(2016) 436-442.

[5] R.E. Rojas-Hernandez, M.A. Rodriguez, F. Rubio-Marcos, A. Serrano, J.F. Fernandez, Designing nanostructured strontium aluminate particles with high luminescence properties, J. Mater. Chem. C 3 (2015) 1268-1276.

[6] C.Q. Wu, J.C. Zhang, P.F. Feng, Y.M. Duan, Z.Y. Zhang, Y.H. Wang, Blue photoluminescence and long lasting phosphorescence properties of a novel chloride phosphate phosphor: $\mathrm{Sr}_{5}\left(\mathrm{PO}_{4}\right)_{3} \mathrm{Cl}: \mathrm{Eu}^{2+}$, J. Lumin. 147 (2014) 229-234.

[7] Y. Liu, J. Kuang, B. Lei and C. Shi, Color-control of long-lasting phosphorescence (LLP) through rare earth ion-doped cadmium metasilicate phosphors, J. Mater. Chem. 15 (2005) 4025-4031.

[8] A. Bessière, A. Lecointre, K. R. Priolkar and D. Gourier, Role of crystal defects in red long-lasting phosphorescence of $\mathrm{CaMgSi}_{2} \mathrm{O}_{6}: \mathrm{Mn}$ diopsides, J. Mater. Chem. 22 (2012) 19039-19046.

[9] T. Matsuzawa, Y. Aoki, N. Takeuchi and Y. Murayama, A New Long Phosphorescent Phosphor with High Brightness, $\mathrm{SrAl}_{2} \mathrm{O}_{4}: \mathrm{Eu}^{2+}, \mathrm{Dy}^{3+}$, J. Electrochem. Soc. 143 (1996) 2670-2673.

[10] B. Viana, S.K. Sharma, D. Gourier, T. Maldiney, E. Teston, D. Scherman, C. Richard, Long term in vivo imaging with $\mathrm{Cr}^{3+}$ doped spinel nanoparticles exhibiting persistent luminescence, J. Lumin. 170 (2016) 879-887.

[11] C. Zhang, X.Y. Gong, R.R. Cui, C.Y. Deng, Improvable luminescent properties by adjusting siliconecalcium stoichiometric ratio in long afterglow phosphors $\mathrm{Ca}_{1.94} \mathrm{MgSi}_{2} \mathrm{O}_{7}: \mathrm{Eu}^{2+}{ }_{0.01}, \mathrm{Dy}^{3+}{ }_{0.05}$, J. Alloys Compd. 658 (2016) 898-903. 
[12] Y. Shen, L.Y. Hou, G.F. Zuo, F.F. Li, Preparation of $\mathrm{ZnO}-\mathrm{B}_{2} \mathrm{O}_{3}-\mathrm{SiO}_{2}: \mathrm{Mn}^{2+}$ optical-storage glass-ceramics with different $\mathrm{ZnF}_{2}$ dopant by sol-gel method, J. Sol-Gel Sci. Technol. 73 (2015) 192-198.

[13] Z.H. Zou, M.X. Duan, H.H. Li, J.C. Zhang, Y.H. Wang, Self-Activated Photostimulated Luminescence Properties and Stable Storage Capacity of Un-Doped Sr3Al2O5Cl2 Material for Potential Applications in Optical Storage, J. Nanosci. Nanotechno. 15 (2015) 7160-7163.

[14] D. Chen, Y. Chen, H. Lu, Z. Ji, A bifunctional Cr/Yb/Tm: $\mathrm{Ca}_{3} \mathrm{Ga}_{2} \mathrm{Ge}_{3} \mathrm{O}_{12}$ phosphor with near-infrared long-lasting phosphorescence and upconversion luminescence, Inorg. Chem. 53 (2014) 8638-8645.

[15] C.B. Wang, T.T. Xuan, J.Q. Liu, H.L. Li, Z. Sun, Long Afterglow $\mathrm{SrAl}_{2} \mathrm{O}_{4}: \mathrm{Eu}^{2+}{ }^{2} \mathrm{Dy}^{3+}$ Phosphors as Luminescent Down-Shifting Layer for Crystalline Silicon Solar Cells, Int. J. Cream. Tehnol. 12 (2015) 722-727.

[16] X.L. Ma, J.C. Zhang, H.H. Li, B.C. Duan, L.N. Guo, M.D. Que, Y.H. Wang, Violet blue long-lasting phosphorescence properties of Mg-doped $\mathrm{BaZrO}_{3}$ and its ability to assist photocatalysis, J. Alloys Compd. 580 (2013) 564-569.

[17] Y.H. Mei, H. Xu, J.C. Zhang, Z.P. Ci, M.X. Duan, S.L. Peng, Z.Y. Zhang, W. Tian, Y. Lu, Y.H. Wang, Design and spectral control of a novel ultraviolet emitting long lasting phosphor for assisting $\mathrm{TiO}_{2}$ photocatalysis: $\mathrm{Zn}_{2} \mathrm{SiO}_{4}: \mathrm{Ga}^{3+}, \mathrm{Bi}^{3+}$, J. Alloys Compd. 622 (2015) 908-912.

[18] Z.W. Pan, Y.Y. Lu, F. Liu, Sunlight-activated long-persistent luminescence in the near-infrared from $\mathrm{Cr}^{3+}$-doped zinc gallogermanates, Nat. Mater. 11 (2012) 58-63. 
[19] P.I. Macfarlane, T.P.J Han, B. Henderson, A.A. Kaminskii, $\mathrm{Cr}^{3+}$ luminescence in calcium and strontium gallogermanate, Opt. Mater. 3 (1994) 15-24.

[20] W.Z. Yan, F. Liu, Y.Y. Lu, X.J. Wang, M. Yin, Z.W. Pan, Near infrared long-persistent phosphorescence in $\mathrm{La}_{3} \mathrm{Ga}_{5} \mathrm{GeO}_{14}: \mathrm{Cr}^{3+}$ phosphor, Opt. Express 18 (2010) 20215-20221.

[21] F. Liu, Y. Liang and Z. Pan, Detection of Up-converted Persistent Luminescence in the Near Infrared Emitted by the $\mathrm{Zn}_{3} \mathrm{Ga}_{2} \mathrm{GeO}_{8}: \mathrm{Cr}^{3+}, \mathrm{Yb}^{3+}, \mathrm{Er}^{3+}$ Phosphor, Phys. Rev. Lett. 113 (2014) 117401.

[22] Y.H. Jin, Y.H. Hu, L. Chen, X.J. Wang, G.F. Ju, Z.F. Mou, Luminescence Properties of Dual-Emission (UV/Visible) Long Afterglow Phosphor $\mathrm{SrZrO}_{3}: \mathrm{Pr}^{3+}$, J. Am. Ceram. Soc. 96 (2013) 3821-3827.

[23] P. Avouris, T.N. Morgan, A tunneling model for the decay of luminescence in inorganic phosphors: The case of $\mathrm{Zn}_{2} \mathrm{SiO}_{4}$ : Mn, J. Chem. Phys. 74 (1981) 4347-4355. [24] W.L. Medlin, Decay of Phosphorescence in $\mathrm{CaCO}_{3}, \mathrm{MgCO}_{3}, \mathrm{CaMg}\left(\mathrm{CO}_{3}\right)_{2}$, and $\mathrm{CaSO}_{4}$, Phys. Rev. 122 (1961) 837-842.

[25] K. Van den Eeckhout, A.J.J. Bos, D. Poelman, P.F. Smet, Revealing trap depth distributions in persistent phosphors, Phys. Rev. B 87 (2013) 045126.

[26] T. Jiang, H. Wang, M.M. Xing, Y. Fu, Y. Peng, X.X. Luo, Luminescence decay evaluation of long-afterglow phosphors, Physica B 450 (2014) 94-98.

[27] Z.H. Zou, J. Wu, H. Xu, J.C. Zhang, Z.P. Ci, Y.H. Wang, How to induce highly efficient long-lasting phosphorescence in a lamp with a commercial phosphor: a facile method and fundamental mechanisms, J. Mater. Chem. C 3 (2015) 8030-8038. 
[28] R. Chen, Glow curves with general order kinetics, J. Electrochem. Soc. 116 (1969) 1254-1257.

[29] G. Kitisy, J.M. Gomez-Rosz, J.W.N. Tuynx, Thermoluminescence glow-curve deconvolution functions for first, second and general orders of kinetics, J. Phys. D: Appl. Phys. 31 (1998) 2636-2641.

\section{Figures captions}

Fig. 1. The results of Rietveld refinement, unit cell / polyhedrons of $\mathrm{Ca}_{2} \mathrm{Ga}_{2} \mathrm{GeO}_{7}$ host. (The black crosses and red solid lines depict the observed and calculated patterns, respectively.)

Fig. 2. The $\mathrm{XRD}$ patterns of the as-synthesized $\mathrm{Ca}_{2} \mathrm{Ga}_{2} \mathrm{GeO}_{7}$ host and the typical $\mathrm{Ca}_{2} \mathrm{Ga}_{2} \mathrm{GeO}_{7}: \mathrm{Pr}^{3+}$ samples.

Fig. 3. The PL excitation (a, $\left.\lambda_{\mathrm{em}}=603 \mathrm{~nm}\right)$, PL emission $\left(\mathrm{b}, \lambda_{\mathrm{em}}=260 \mathrm{~nm}\right)$ and LPL (c, recorded after UV lamp irradiation for $60 \mathrm{~s}$ and again after a delay of $30 \mathrm{~s}$ ) spectra of the typical $\mathrm{Ca}_{2} \mathrm{Ga}_{2} \mathrm{GeO}_{7}: 0.1 \% \mathrm{Pr}^{3+}$ sample.

Fig. 4. The LPL spectra and CIE coordinates of the $\mathrm{Ca}_{2} \mathrm{Ga}_{2} \mathrm{GeO}_{7}: x \operatorname{Pr}^{3+}(x=0.06 \%$, 0.08\%, 0.1\%, 0.3\%, and 0.5\%, respectively) samples measured after UV (254 nm) lamp irradiation for 60s and again after a delay of $30 \mathrm{~s}$. The LPL image of the optimal $\mathrm{Ca}_{2} \mathrm{Ga}_{2} \mathrm{GeO}_{7}: 0.1 \% \mathrm{Pr}^{3+}$ sample after UV irradiation for $60 \mathrm{~s}$ in dark condition.

Fig. 5. The LPL decay curves of the $\mathrm{Ca}_{2} \mathrm{Ga}_{2} \mathrm{GeO}_{7}: \mathrm{xPr}^{3+}(\mathrm{x}=0.06 \%, 0.08 \%, 0.1 \%$, $0.3 \%$, and $0.5 \%$, respectively) samples (a) which were recorded immediately after UV (254 nm) lamp irradiation for $15 \mathrm{~min}$. The LPL fitting curves of 
Ca2Ga2GeO7:0.1\%Pr3+ in single (b) , double (c) logic diagrams, and reciprocal function (d).

Fig. 6. The TL curves of the $\mathrm{Ca}_{2} \mathrm{Ga}_{2} \mathrm{GeO}_{7}$ host (a) and the $\mathrm{Ca}_{2} \mathrm{Ga}_{2} \mathrm{GeO}_{7}: x \mathrm{Pr}^{3+}(\mathrm{b}, x=$ $0 \%, 0.06 \%, 0.08 \%, 0.1 \%, 0.3 \%$, and $0.5 \%$, respectively) samples recorded immediately after UV lamp irradiation for 15 min. The deconvolution of the TL glow curve of the optimal $\mathrm{Ca}_{2} \mathrm{Ga}_{2} \mathrm{GeO}_{7}: 0.1 \% \mathrm{Pr}^{3+}$ sample (c).

Fig. 7. The TL glow curves of the optimal $\mathrm{Ca}_{2} \mathrm{Ga}_{2} \mathrm{GeO}_{7}: 0.1 \% \mathrm{Pr}^{3+}$ sample after UV irradiation for 15 min and then after different delay times, and the calculated traps depths by a classic multi-peak fitting method based on general-order kinetics.

Fig. 8. The LPL mechanism of the as-synthesized $\mathrm{Ca}_{2} \mathrm{Ga}_{2} \mathrm{GeO}_{7}: \mathrm{Pr}^{3+}$ phosphor. 
Table 1 Refined crystallographic data of $\mathrm{Ca}_{2} \mathrm{Ga}_{2} \mathrm{GeO}_{7}$.

\begin{tabular}{ll}
\hline Formula & $\mathrm{Ca}_{2} \mathrm{Ga}_{2} \mathrm{GeO}_{7}$ \\
Crystal system & tetragonal \\
Space group & $\mathrm{P}-421 \mathrm{~m}(113)$ \\
Lattice parameters $/ \AA$ & $\mathrm{a}=\mathrm{b}=7.8938(0)$ \\
& $\mathrm{c}=5.2096(0)$ \\
Cell volume $/ \AA^{3}$ & $324.62(0)$ \\
Formula units $/$ cell & 24 \\
$\mathrm{Z}$ & 2 \\
$\rho_{\text {calcd }} / \mathrm{g} \cdot \mathrm{cm}^{-3}$ & 4.13473 \\
$\mathrm{~T} / \mathrm{K}$ & $293(1)$ \\
Diffractometer & $\mathrm{Rigaku} \mathrm{D} / \mathrm{Max}-2400$ \\
Radiation $/ \AA$ & $\mathrm{Cu}-\mathrm{K}_{\alpha}(\lambda=1.5405)$ \\
Absorption correction & multi-scan \\
$2 \theta$ range $/{ }^{\circ}$ & $8.00234-141.006$ \\
Index ranges & $-7<\mathrm{h}<7$ \\
& $-4<\mathrm{k}<4$ \\
Refined parameters & $-4<1<4$ \\
Goodness of fit $/ \chi^{2}$ & 156 \\
wRp & 1.771 \\
Rp & $9.30 \%$ \\
\hline
\end{tabular}


Table 2 Refined coordinates of all atoms and the unit cell parameters of the $\mathrm{Ca}_{2} \mathrm{Ga}_{2} \mathrm{GeO}_{7}$ host as determined by the GSAS program.

\begin{tabular}{cccccc}
\hline $\begin{array}{c}\text { Ion } \\
\text { coordinates }\end{array}$ & $\mathbf{x}$ & $\mathbf{y}$ & $\mathbf{z}$ & Occupancy & $\mathbf{U}_{\text {iso }}$ \\
\hline $\mathrm{Ca} 1$ & $0.160(1)$ & $0.660(1)$ & $0.488(2)$ & $1.000(0)$ & $0.036(2)$ \\
$\mathrm{Ga} 1$ & $0.000(0)$ & $0.000(0)$ & $0.000(0)$ & $1.000(0)$ & $0.023(2)$ \\
$\mathrm{Ga} 2$ & $0.355(1)$ & $0.855(1)$ & $0.037(1)$ & $0.500(0)$ & $0.046(8)$ \\
$\mathrm{Ge} 1$ & $0.355(1)$ & $0.855(1)$ & $0.037(1)$ & $0.500(0)$ & $0.006(4)$ \\
$\mathrm{O} 1$ & $0.090(2)$ & $0.161(2)$ & $0.798(3)$ & $1.000(0)$ & $0.039(4)$ \\
$\mathrm{O} 2$ & $0.358(2)$ & $0.858(2)$ & $0.708(3)$ & $1.000(0)$ & $0.044(6)$ \\
$\mathrm{O} 3$ & $0.000(0)$ & $0.500(0)$ & $0.810(5)$ & $1.000(0)$ & $0.013(6)$
\end{tabular}


Table 3 Refined bond lengths in $\mathrm{Ca}_{2} \mathrm{Ga}_{2} \mathrm{GeO}_{7}$ host.

\begin{tabular}{cccc}
\hline Vector & Length $\AA$ & Vector & Length $\AA$ \\
\hline Ca1-O1 & $2.47(2)$ & Ga1-O1 & $1.80(1)$ \\
Ca1-O1 & $2.91(2)$ & Ga1-O1 & $1.80(1)$ \\
Ca1-O1 & $2.47(2)$ & Ga1-O1 & $1.80(1)$ \\
Ca1-O1 & $2.91(2)$ & Ga1-O1 & $1.80(1)$ \\
Ca1-O2 & $2.48(2)$ & Ga2(Ge1)-O1 & $1.81(1)$ \\
Ca1-O2 & $2.61(2)$ & Ga2(Ge1)-O1 & $1.81(1)$ \\
Ca1-O2 & $2.61(2)$ & Ga2(Ge1)-O2 & $1.71(2)$ \\
$\mathrm{Ca} 1-\mathrm{O} 3$ & $2.45(3)$ & Ga2(Ge1)-O3 & $1.80(2)$ \\
\hline
\end{tabular}


Table 4 The final intensity $\left(I_{0}\right)$, constant $(A)$ and decay time $(\tau)$ of typical $\mathrm{Ca}_{2} \mathrm{Ga}_{2} \mathrm{GeO}_{7}: 0.1 \% \mathrm{Pr}^{3+}$.

\begin{tabular}{ccccc}
\hline$I_{0}\left(\mathrm{mcd} / \mathrm{m}^{2}\right)$ & $A_{1}\left(\mathrm{mcd} / \mathrm{m}^{2}\right)$ & $\tau_{1}(\mathrm{~s})$ & $A_{2}\left(\mathrm{mcd} / \mathrm{m}^{2}\right)$ & $\tau_{2}(\mathrm{~s})$ \\
\hline $1.0759 \pm 0.0324$ & $13.4078 \pm 0.2211$ & $116.1998 \pm 2.2478$ & $101.6437 \pm 2.4086$ & $9.2247 \pm 0.1704$ \\
\hline
\end{tabular}




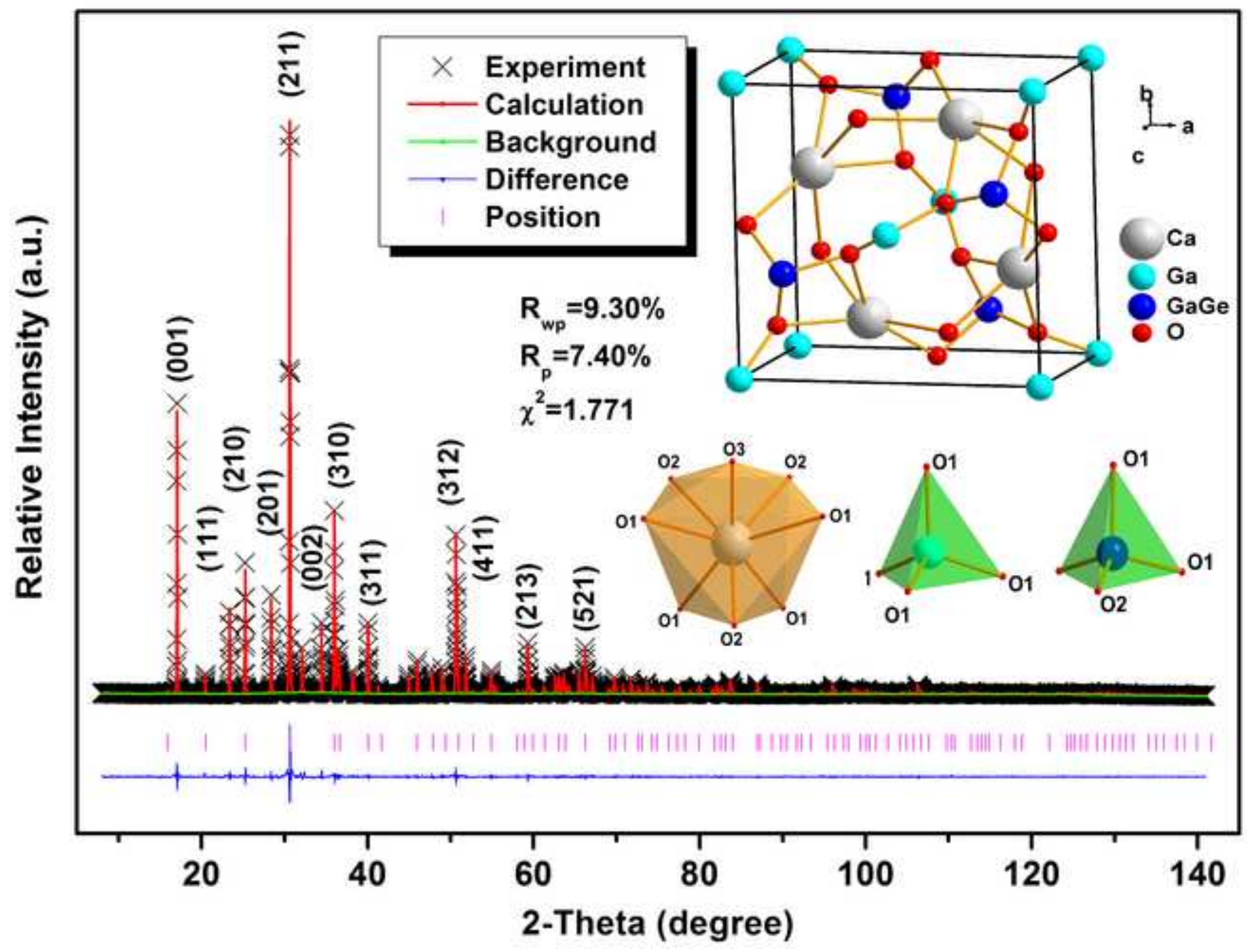




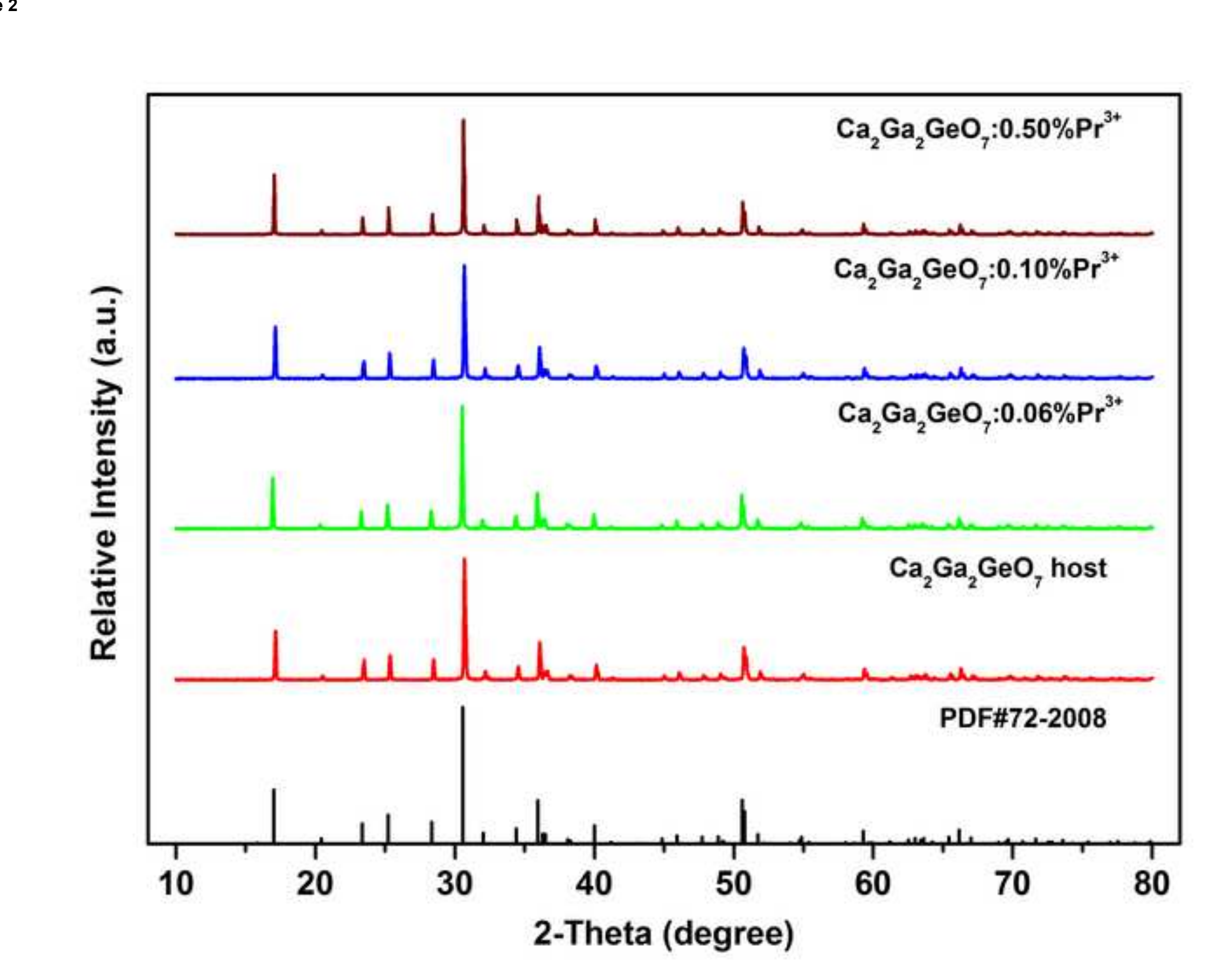

促

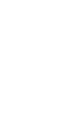




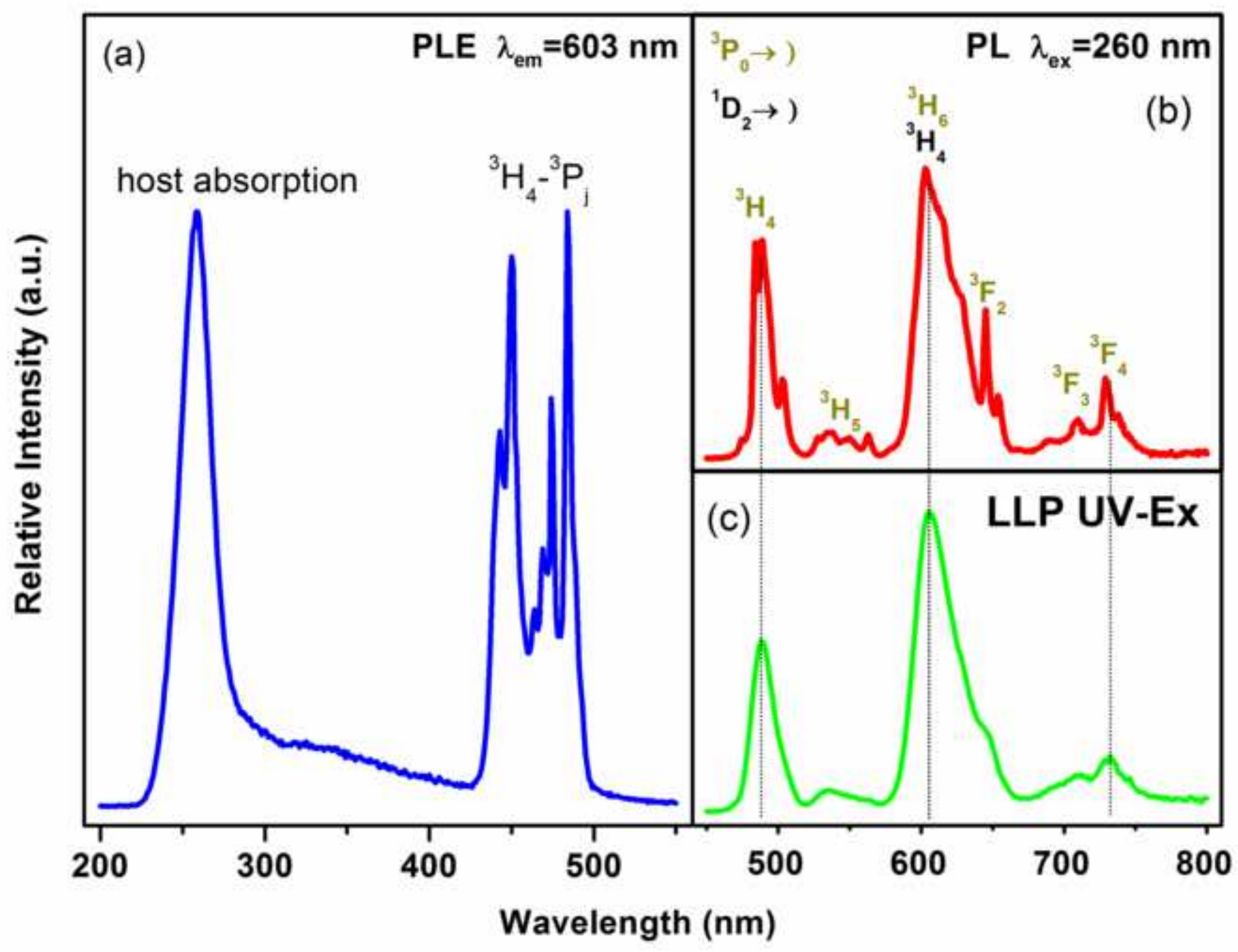




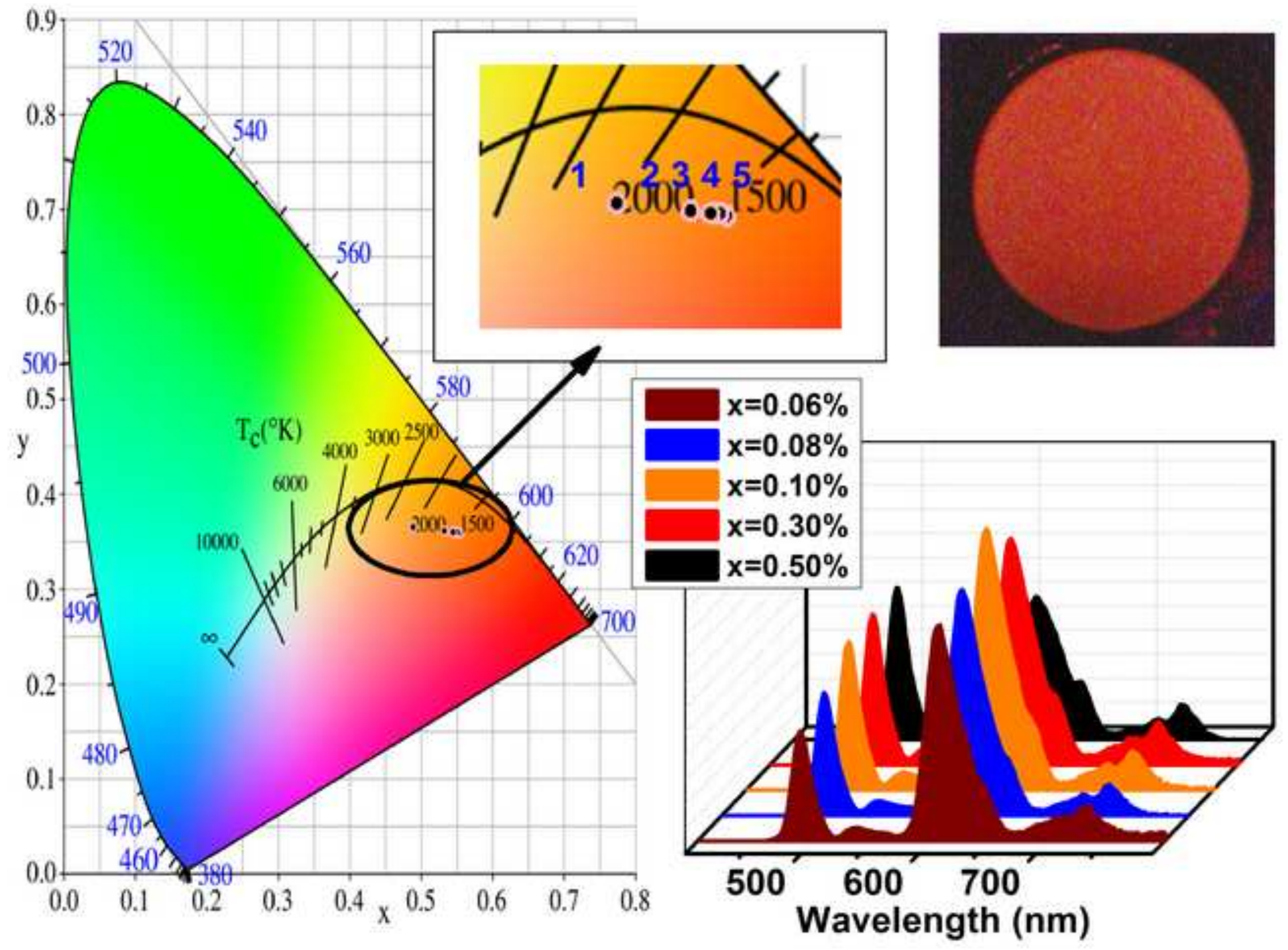

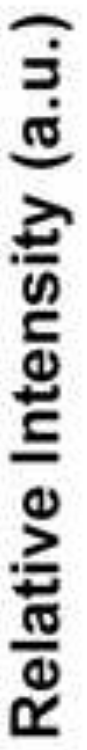




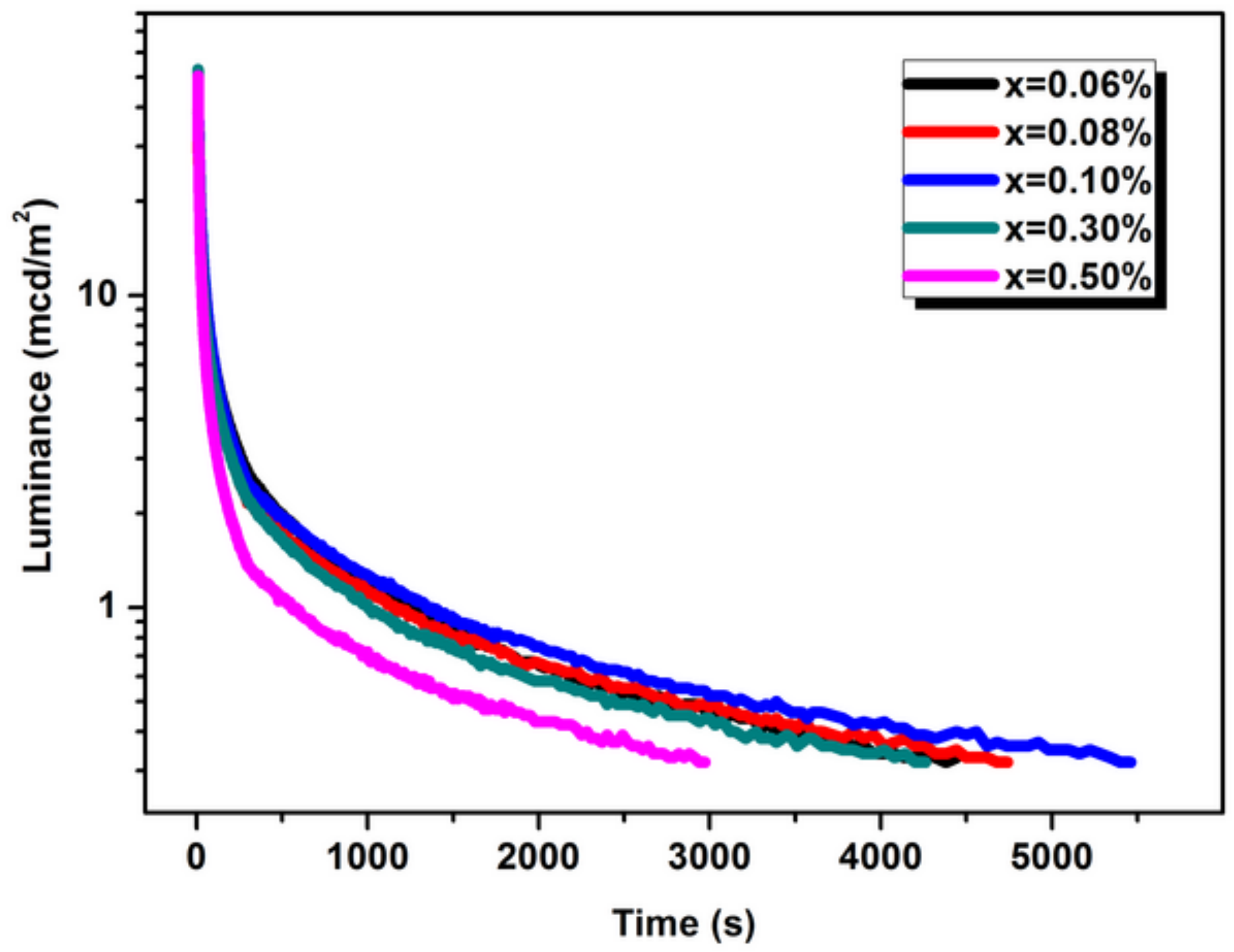



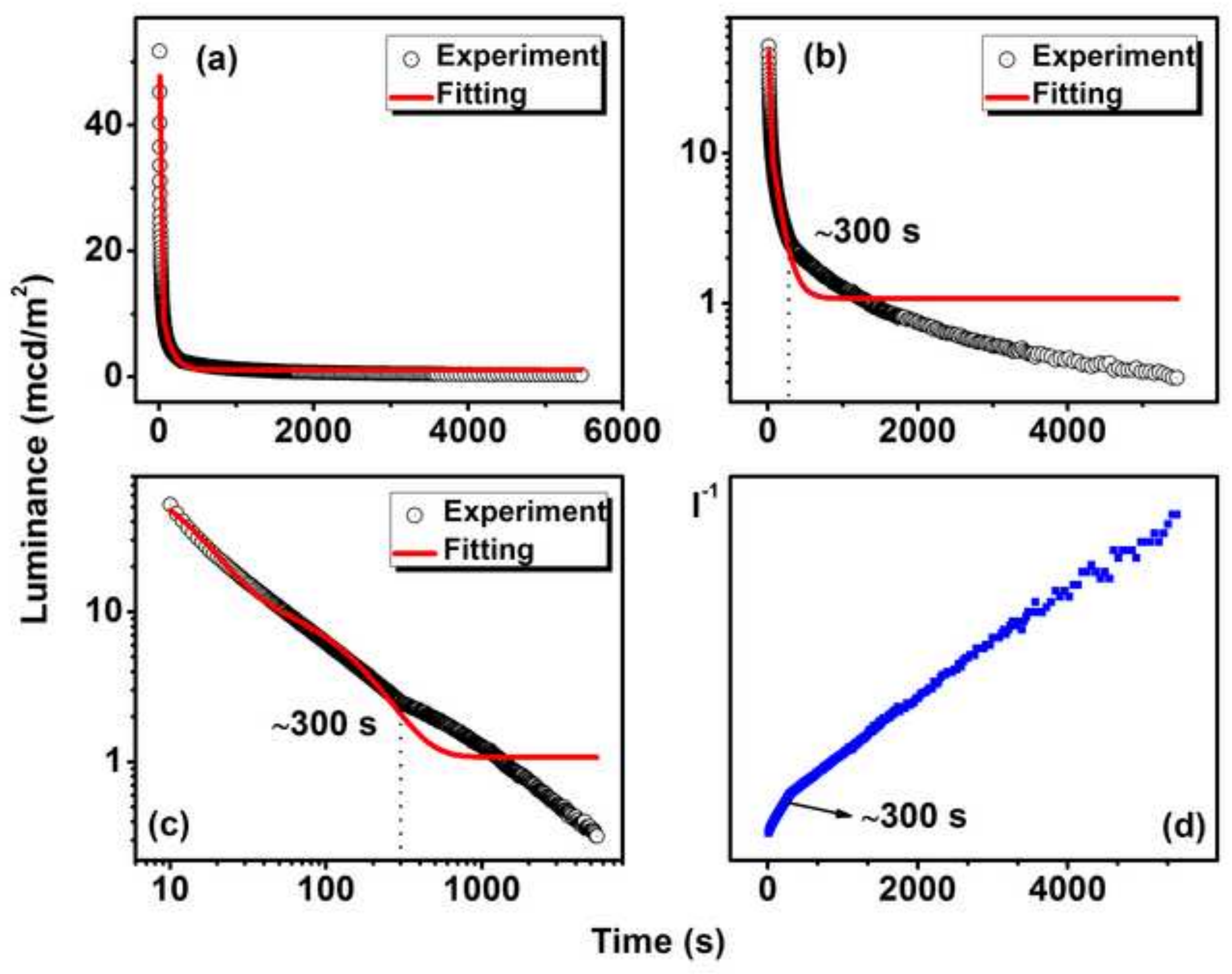

Time (s) 


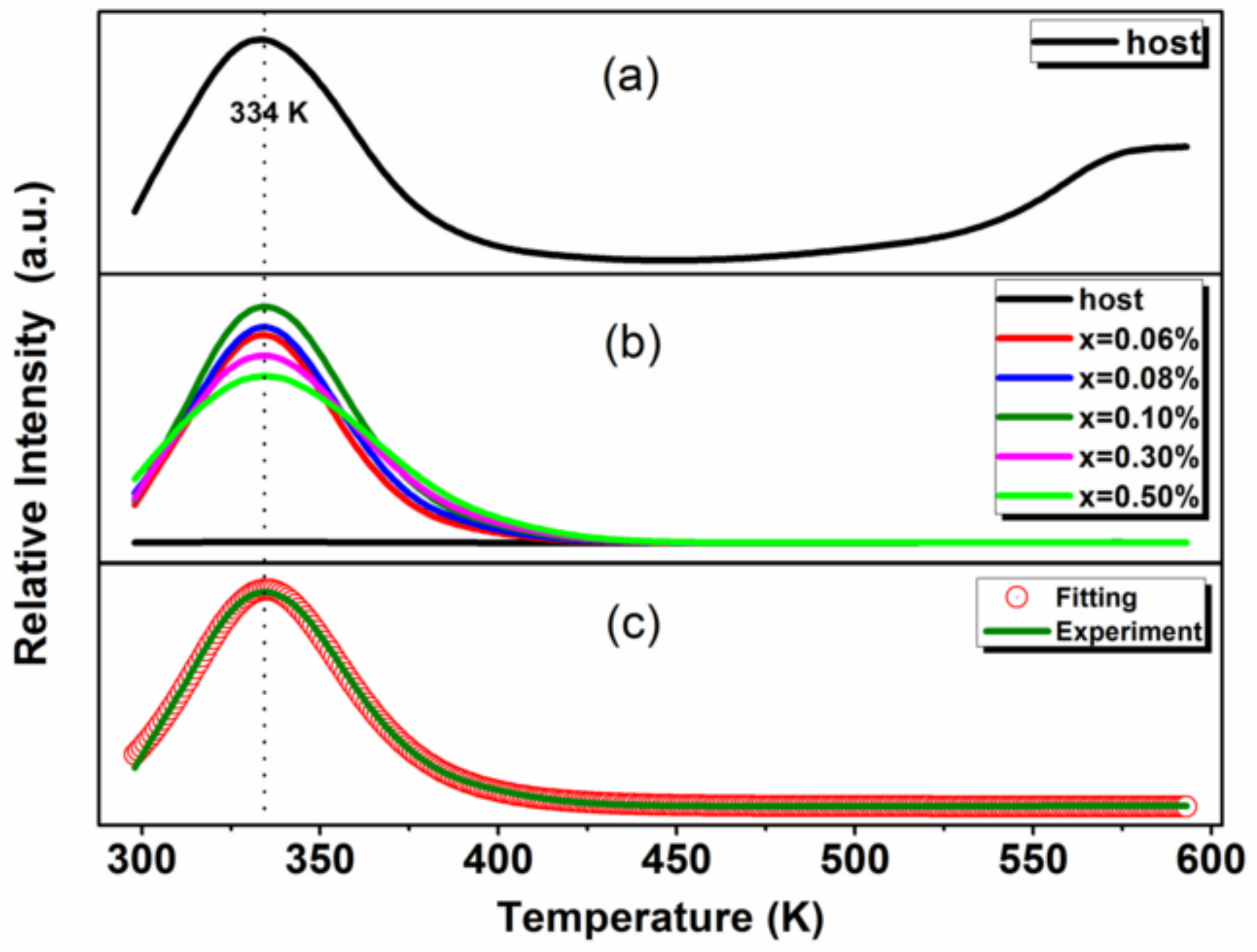




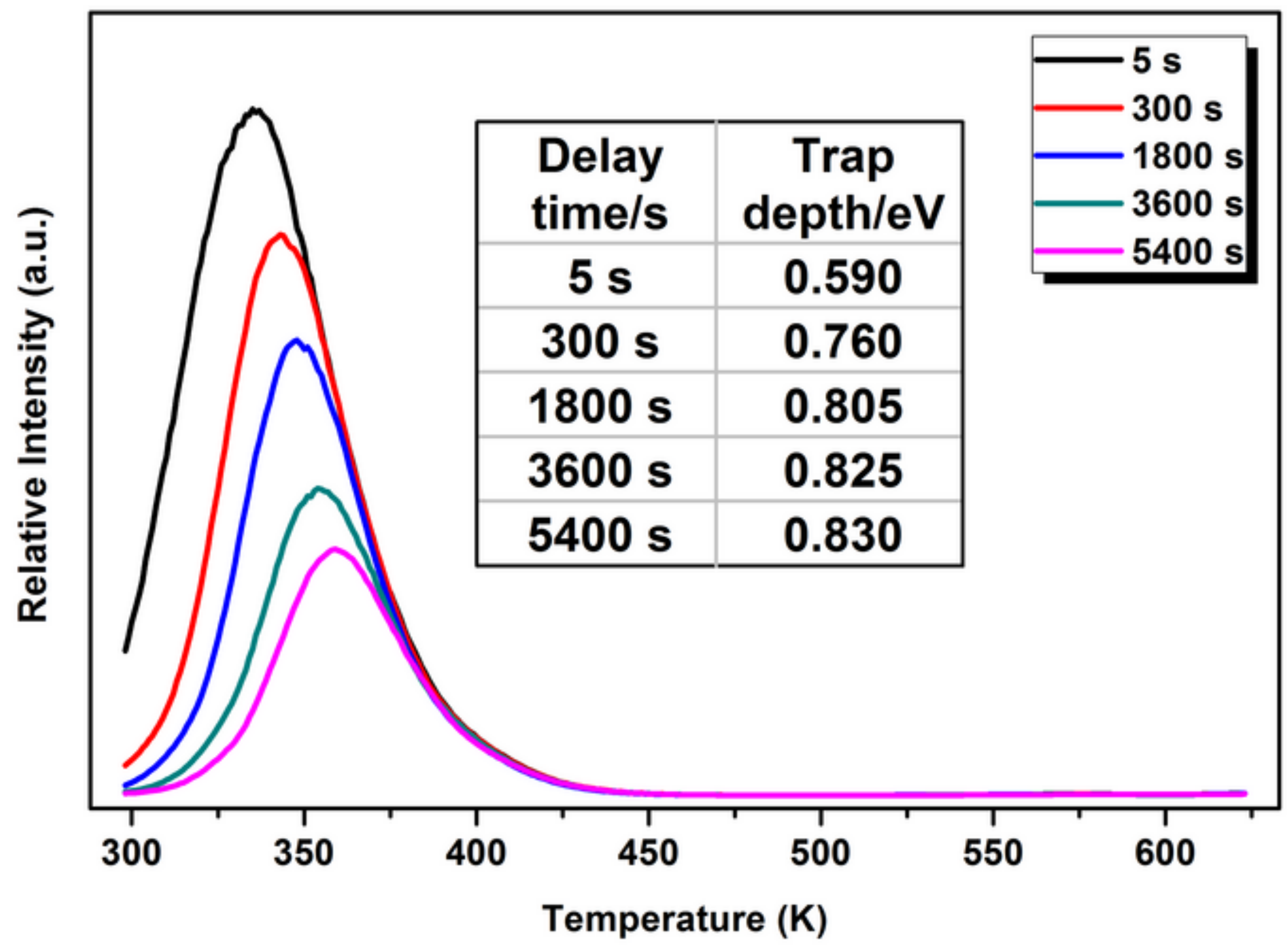




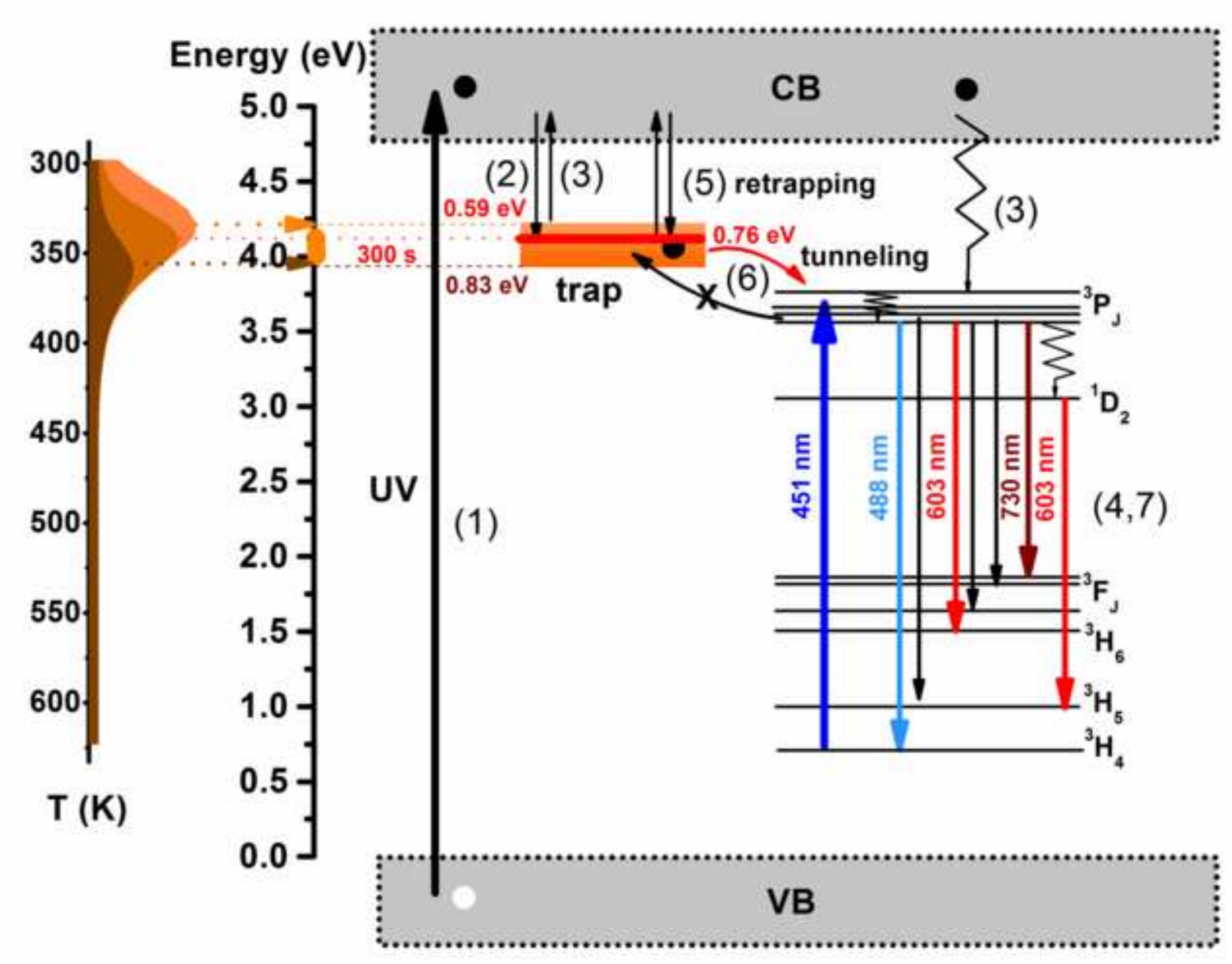



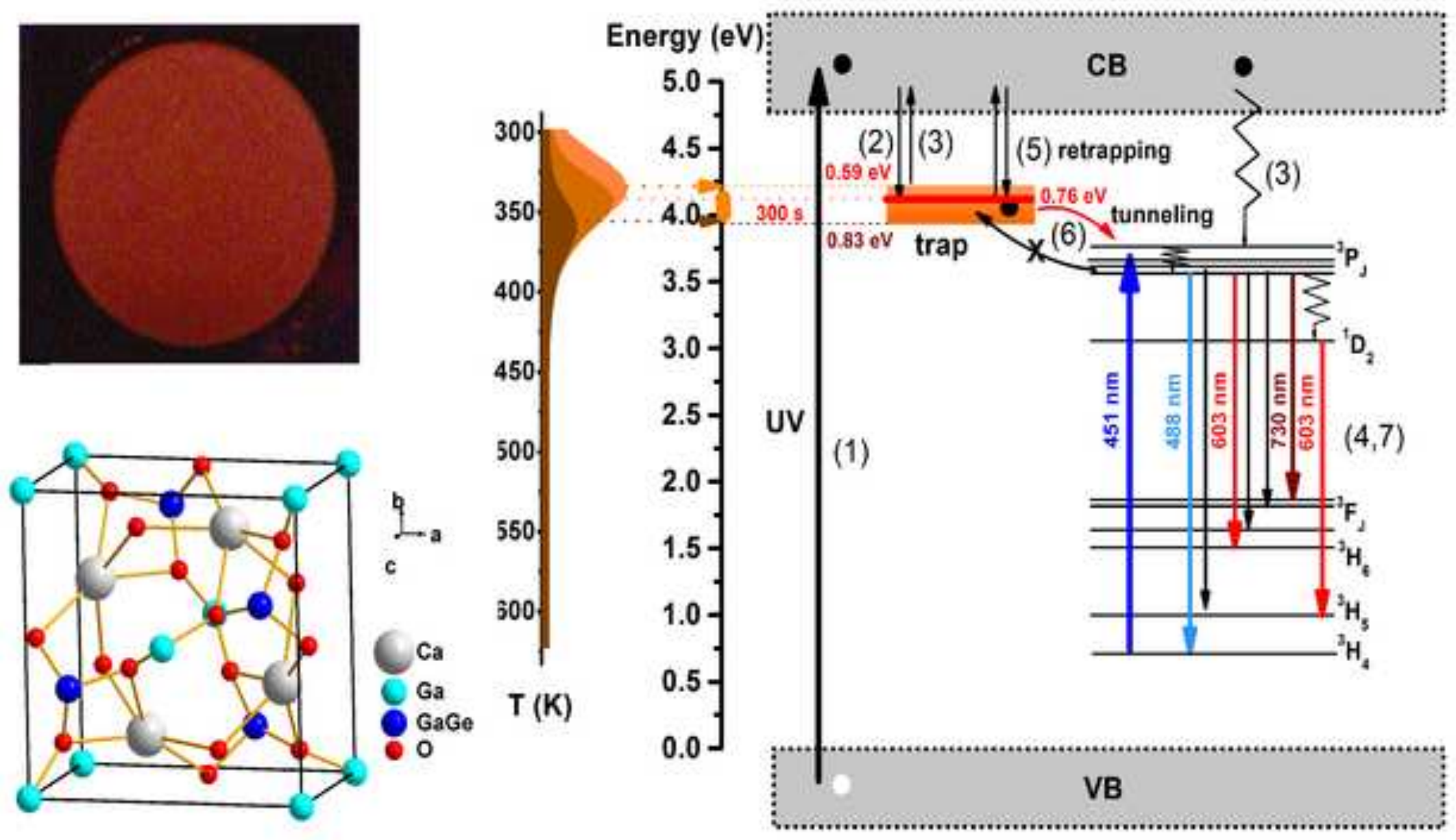